\title{
Augmented antifungal potential of benzothiazol-2- ylcarbamodithioates as hybrid-silver aqua nanoformulations
}

\author{
Anjali Sidhu $^{1} \cdot$ Suman R. Ghatelwal ${ }^{1} \cdot$ Khushbu Gumber $^{1} \cdot$ Anju Bala $^{2}$
}

Received: 22 July 2017/ Accepted: 14 September 2017/Published online: 22 September 2017

(c) The Author(s) 2017. This article is an open access publication

\begin{abstract}
This study was focused on the preparation of benzothiazol-2-ylcarbamodithioates-silver nanoconjugates (BCDTC-AgNPs) for their in vitro antifungal evaluation against various phytopathogenic fungi viz. Pyricularia grisea, Drechslera oryzae, Fusarium moniliforme and Ustilaginoidea virens. Benzothiazol-2-ylcarbamodithioates (BCDTCs) were used both as capping as well as stabilizing for silver nanoparticles (AgNPs). The prepared nanoconjugates were analysed by UV-visible and TEM studies. The comparative antifungal evaluation of BCDTC-AgNPs with precursor BCDTCs and AgNPs indicated the manifold increase in antifungal potential when applied as nanoconjugates. The promising results were comparable to the standard commercial fungicides Tilt and Bavistin, in most of the cases.
\end{abstract}

Keywords Benzothiazol-2-ylcarbamodithioates (BCDTCs) - Silver nanoparticles (AgNPs) · Capping agent $\cdot$ Stabilizing agent $\cdot$ Antifungal potential . Phytopathogenic fungi

\section{Introduction}

Conventional formulations of bioactive organic compounds (suspension or emulsion) suffer from limitations of low or zero water dispersibility, high dose of applications, low

Khushbu Gumber

khushbugumber8@gmail.com

1 Department of Chemistry, Punjab Agricultural University, Ludhiana, India

2 Department of Plant Breeding and Genetics, Punjab Agricultural University, Ludhiana, India bioavailability, instability and usually inability of producing the sustained effects. Nanotechnical methodologies of application of bioactive materials as their conjugates with metal nanocarriers (Kora and Rastogi 2013) or their loading on metal nanoparticles is a matter of intense interest (Duncan 2003; Ferrari 2005) and most pertinently emerging field. Nanoconjugates showed significant enhancement in biological activity in comparison to free drug molecules because of dispersion of organic molecules on the metal nanoparticle surface (Bordes et al. 2009; Gajbhiye et al. 2009; Saha et al. 2016). This is also attributable to advanced morpho-topological properties as well as inherent biological properties of metal nanoparticles (Kanhed et al. 2014; Liversidge et al. 2003).

Among metal nanoparticles, silver nanoparticles is eliciting area of interest due to its hypotoxicity (Stewart and Costerton 2001; Fabrega et al. 2011), efficient biopotential (Lok et al. 2006) and no resistance-causing behaviour (Stewart and Costerton 2001), along with a unique physical, chemical and morpho-topological properties, leading to their diverse and augmented biological potencies. Silver nanoparticles are referred as magic bullets which take the bioactive materials into the interior of the cell surface (Faraji and Wipf 2009), thus providing an increased scope of biological potential of bioactive compounds at low concentrations (Neu 1992). Wide variety of capping and stabilizing agents are used for AgNPs, which affect their size, distribution and bioactivity. Thio compounds among them act as excellent surface stabilizing agents for the soft metal nanoparticles, owing to their soft acid-soft base stabilizing interactions (Tong et al. 2006; Vyas et al. 2015).

Our previous results on the synthesis of novel hybrid organic molecules as antifungals, series of benzothiazol-2ylcarbamodithioates (Sidhu et al. 2016; Ghatelwal et al. 
2017) based on the concept of lead hybridization (Sidhu et al. 2015; Sidhu and Kukreja 2015; Gumber et al. 2015; Kukreja et al. 2016) inflicted remarkable antifungal properties. But low water dispersibility and low stability of carbamodithioates, as well as remarkable potential of medicine-nanosilver hybrids impelled us for their modification as benzothiazol-2-ylcarbamodithioates-silver nanoconjugates, as ecofriendly aqua colloidal solutions. Mycocidal potential of benzothiazol-2-ylcarbamodithioates-Ag nanoconjugates against various phytopathogenic fungi were compared with naked AgNPs and benzothiazol-2-ylcarbamodithioates, to observe the effect of nanoconjugation. The simple structural activity relationship (SAR) was established in this paper.

\section{Materials and methods}

\section{Instruments and measurements}

The UV-Vis absorption spectra were recorded on UV 1800 Shimadzu double beam spectrophotometer over the wavelength range of 300-700 nm using quartz cuvettes of $1 \mathrm{~cm}$ path length. The size of nanoparticles was studied in Hitachi transmission electron microscope at an accelerated voltage of $200 \mathrm{kV}$. Benzo[d]thiazol-2-ylcarbamodithioates (BCDTCs) (1-8) were synthesized by previously standardized work of our lab (Sidhu et al. 2016; Ghatelwal et al. 2017) and the purity of the compounds were checked by TLC using Merck silica gel 60 F254 and visualized by exposure to iodine vapours or UV light. Series of BCDTCs included butyl (6-chlorobenzo[d]thiazol-2-yl)carbamodithioate (1), decyl (6-chlorobenzo[d]thiazol-2-yl)carbamodithioate (2), hexyl (6-chlorobenzo[d]thiazol-2yl)carbamodithioate (3), octyl (6-chlorobenzo[d]thiazol2-yl)carbamodithioate (4), butyl (6-fluorobenzo[d]thiazol-2 -yl)carbamodithioate (5), decyl (6-fluorobenzo[d]thiazol2-yl)carbamodithioate (6), hexyl (6-fluorobenzo[d]thiazol-2 -yl)carbamodithioate (7) and octyl (6-fluorobenzo[d]thiazol2-yl)carbamodithioate (8).

\section{Synthesis of silver nanoparticles (AgNPs)}

A $10-\mathrm{ml}$ volume of $1.0 \mathrm{mM}$ silver nitrate was added dropwise (about 1 drop per second) to $30 \mathrm{ml}$ of $5.0 \mathrm{mM}$ sodium borohydride solution while sonication, which was continued for another $5 \mathrm{~min}$. The solution turned light yellow after the addition of silver nitrate which was primary indication for the synthesis of silver nanoparticles (Aashritha 2013). It was further analysed and confirmed on the basis of UV-visible and TEM analysis.
Synthesis and optimization of benzo[d]thiazol-2ylcarbamodithioate-capped silver nanoparticles (BCDTC$A g N P^{1-8}$ )

Prior to the synthesis of all the capped silver nanoparticles, the exact concentration required for uniform capping of naked AgNPs with complete stability was optimised. The experiment was performed in quadruplet using different concentrations viz. $0.015,0.030,0.045$ and $0.060 \mathrm{mmol}$ of benzo[d]thiazol-2-ylcarbamodithioates (1 and 2) in $10 \mathrm{ml}$ of $25 \times 10^{-6} \mathrm{M}$ AgNPs.

Different concentrations of benzo[d]thiazol-2-ylcarbamodithioates ( 1 and 2 ) were dissolved in minimum volume of DMSO and added to $10 \mathrm{ml}$ of $25 \times 10^{-6} \mathrm{M}$ naked silver nanoparticle solution under sonication to obtain the benzo[d]thiazol-2-ylcarbamodithioate-capped silver nanoparticles. The concentration optimization was made on the basis of UV-visible spectrophotometric results and TEM micrographs. The experiment with optimized concentration was repeated for compound 3-8 to obtain the series of $\mathrm{BCDTC}-\mathrm{AgNP}^{\mathbf{1 - 8}}$.

\section{Toxicity analysis}

Toxtree v2.6.6, an open-source software application was used to analyse the toxic effect of different molecules. In order to find out the toxic hazards, two-dimensional models of all the synthesized compounds were first converted into its simplified molecular-input line-entry system (SMILES format) using the online SMILE converter. Then SMILES code was simply put into the Chemical identifier row available in the Toxtree software, to get the toxic characters of the molecule.

\section{Antifungal evaluation}

The in vitro antifungal activity of all the titled compounds was evaluated against four phytopathogenic fungi viz. Pyricularia grisea, Drechslera oryzae, Fusarium moniliforme and Ustilaginoidea virens and compared with the standard fungicides Tilt (1-[[2-(2,4-dichlorophenyl)-4-propyl-1,3dioxolan-2-yl]methyl]-1H-1,2,4-triazole) and Bavistin $50 \mathrm{WP}$ (methyl-2-benzimidazole-2-ylcarbamate). The isolates of phytopathogenic fungi were provided by the Plant Pathology Department of the Punjab Agricultural University and the standards Tilt and Bavistin, that served as the positive control, were obtained from their respective manufacturers.

The concentration of prepared naked silver nanoparticles and benzo[d]thiazol-2-ylcarbamodithioates-capped silver nanoparticles $\left(\mathrm{BCDTC}-\mathrm{AgNP}^{\mathbf{1 - 8}}\right)$ were $25 \times 10^{-6} \mathrm{M}$ 
and the nanoconjugates formed by adding optimized concentration of BCDTC were used as such as a stock solution. The required dilutions were subsequently made from the stock solution by adding distilled water, as and when required. The in vitro effective concentrations of the compounds were determined by Spore germination inhibition technique. For assays, $0.02 \mathrm{ml}$ of the title compounds to be tested and $0.02 \mathrm{ml}$ of spore suspension were seeded in the cavity of the cavity slide and incubated at $15 \pm 2{ }^{\circ} \mathrm{C}$. Growth was determined at $24 \mathrm{~h}$ for all the phytopathogenic fungi. The $\mathrm{EC}_{50}$ values (concentration which induces a response halfway) were calculated using the probit analysis
(Finney 1971). The data points are the mean of triplicates. The results of assay along with the data of BCDTC (1-8) obtained from the earlier laboratory studies are summarized in Tables 1 and 2.

\section{Results and discussion}

The benzothiazol-2ylcarbamodithioates (1-8) prepared by two-step reaction protocol (Scheme 1) were obtained from the laboratory stock.

Table $1 \mathrm{EC}_{50}$ values of BCDTC-AgNP ${ }^{1-8}$ nanohybrids in terms of molar equivalency of AgNps (in $\mu \mathrm{mol} / \mathrm{ml}$ )

\begin{tabular}{|c|c|c|c|c|}
\hline Compd/BCDTC-AgNPs & $\begin{array}{l}\text { P. grisea } \\
\mathrm{EC}_{50} \text { values (in } \mu \mathrm{mol} / \mathrm{ml} \text { ) }\end{array}$ & D. oryzae & F. moniliforme & U. virens \\
\hline BCDTC-AgNP ${ }^{1}$ & $0.31 \times 10^{-3}$ & $0.10 \times 10^{-3}$ & $0.10 \times 10^{-3}$ & $0.12 \times 10^{-3}$ \\
\hline BCDTC-AgNP ${ }^{2}$ & $0.37 \times 10^{-3}$ & $>1.24 \times 10^{-3}$ & $0.36 \times 10^{-3}$ & $>1.24 \times 10^{-3}$ \\
\hline BCDTC-AgNP 3 & $0.20 \times 10^{-3}$ & $0.17 \times 10^{-3}$ & $0.33 \times 10^{-3}$ & $0.174 \times 10^{-3}$ \\
\hline BCDTC-AgNP ${ }^{4}$ & $>1.24 \times 10^{-3}$ & $0.37 \times 10^{-3}$ & $>1.24 \times 10^{-3}$ & $0.224 \times 10^{-3}$ \\
\hline BCDTC-AgNP ${ }^{5}$ & $0.13 \times 10^{-3}$ & $0.18 \times 10^{-3}$ & $0.16 \times 10^{-3}$ & $0.11 \times 10^{-3}$ \\
\hline BCDTC-AgNP ${ }^{6}$ & $>1.24 \times 10^{-3}$ & $0.35 \times 10^{-3}$ & $0.37 \times 10^{-3}$ & $0.36 \times 10^{-3}$ \\
\hline BCDTC-AgNP ${ }^{7}$ & $0.37 \times 10^{-3}$ & $0.22 \times 10^{-3}$ & $0.32 \times 10^{-3}$ & $0.33 \times 10^{-3}$ \\
\hline BCDTC-AgNP ${ }^{8}$ & $0.29 \times 10^{-3}$ & $>1.24 \times 10^{-3}$ & $0.31 \times 10^{-3}$ & $0.27 \times 10^{-3}$ \\
\hline Naked AgNPs & $>25 \times 10^{-3}$ & $>25 \times 10^{-3}$ & $>25 \times 10^{-3}$ & $>25 \times 10^{-3}$ \\
\hline Bavistin $^{a}$ & - & - & 0.78 & - \\
\hline Tilt $^{\mathrm{b}}$ & 0.20 & 0.15 & - & 0.18 \\
\hline
\end{tabular}

${ }^{a}$ Standard fungicide against $F$. moniliforme

${ }^{\mathrm{b}}$ Standard fungicide against $P$. grisea, $U$. virens and $D$. oryzae

Table 2 Comparative $\mathrm{EC}_{50}$ values of $\mathrm{BCDTC}$ (compound 1-8) verses drug equivalence of $\mathrm{BCDTC}$ in $\mathrm{BCDTC}-\mathrm{AgNP}^{\mathbf{1 - 8}}$ nanohybrids (in $\mu \mathrm{mol} /$ $\mathrm{ml})$

\begin{tabular}{|c|c|c|c|c|}
\hline Compd/BCDTC-AgNPs & $\begin{array}{l}P . \text { grisea } \\
\text { EC }_{50} \text { values (in } \mu \mathrm{mol} / \mathrm{ml} \text { ) }\end{array}$ & D. oryzae & F. moniliforme & $U$. virens \\
\hline Compd 1/BCDTC-AgNP ${ }^{1}$ & $0.76 / 0.187$ & $0.13 / 0.062$ & $0.32 / 0.062$ & $0.58 / 0.075$ \\
\hline Compd 2/BCDTC-AgNP ${ }^{2}$ & $0.69 / 0.225$ & $1.45 />0.75$ & $0.58 / 0.215$ & $1.73 />0.75$ \\
\hline Compd 3/BCDTC-AgNP 3 & $0.67 / 0.120$ & $0.20 / 0.105$ & $0.90 / 0.200$ & $0.69 / 0.105$ \\
\hline Compd 4/BCDTC-AgNP 4 & $0.82 />0.75$ & $2.40 / 0.225$ & $1.40 />0.75$ & $1.32 / 0.135$ \\
\hline Compd 5/BCDTC-AgNP & $0.38 / 0.075$ & $0.23 / 0.110$ & $1.13 / 0.095$ & $0.65 / 0.065$ \\
\hline Compd 6/BCDTC-AgNP & $1.08 />0.75$ & $1.00 / 0.215$ & $1.16 / 0.225$ & $1.48 / 0.215$ \\
\hline Compd 7/BCDTC-AgNP ${ }^{7}$ & $0.52 / 0.225$ & $2.11 / 0.135$ & $1.12 / 0.195$ & $0.74 / 0.200$ \\
\hline Compd 8/BCDTC-AgNP & $0.78 / 0.175$ & $2.56 />0.75$ & $1.17 / 0.187$ & $1.31 / 0.162$ \\
\hline Naked AgNPs & c & $\mathrm{c}$ & $\mathrm{c}$ & c \\
\hline Bavistin $^{a}$ & - & - & 0.78 & - \\
\hline Tilt $^{\mathrm{b}}$ & 0.20 & 0.15 & - & 0.18 \\
\hline
\end{tabular}

${ }^{\text {a }}$ Standard fungicide against $F$. moniliforme

${ }^{\mathrm{b}}$ Standard fungicide against $P$. grisea, $U$. virens and $D$. oryzae

${ }^{\mathrm{c}}$ Naked AgNps were inactive at $25 \times 10^{-3} \mu \mathrm{mol}$ concentration 

benzo[d]thiazol2ylcarbamodithioates (BCDTCs) (1-8)
Scheme 1 Synthesis of

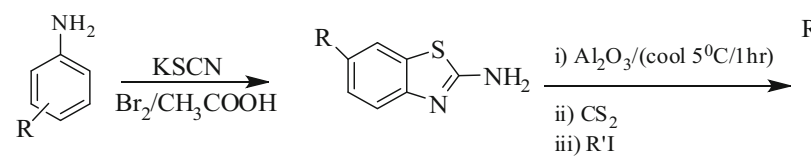
$\overbrace{N}^{\mathrm{R}} \backslash-\mathrm{N}-\mathrm{C}^{\mathrm{S}}-\mathrm{S}-\mathrm{R}$
(1-8)

$1, \mathrm{R}=-\mathrm{Cl}, \mathrm{R}^{\prime}=-\mathrm{C}_{4} \mathrm{H}_{9}$,

$2, \mathrm{R}=-\mathrm{Cl}, \mathrm{R}^{\prime}=-\mathrm{C}_{10} \mathrm{H}_{21}$

$3, \mathrm{R}=-\mathrm{Cl}, \mathrm{R}^{\prime}=-\mathrm{C}_{6} \mathrm{H}_{13}$

$4, \mathrm{R}=-\mathrm{Cl}, \mathrm{R}^{\prime}=-\mathrm{C}_{8} \mathrm{H}_{17}$,

$5, \mathrm{R}=-\mathrm{F}, \mathrm{R}^{\prime}=-\mathrm{C}_{4} \mathrm{H}_{9}$

$6, \mathrm{R}=-\mathrm{F}, \mathrm{R}^{\prime}=-\mathrm{C}_{10} \mathrm{H}_{21}$,

$7, \mathrm{R}=-\mathrm{F}, \mathrm{R}^{\prime}=-\mathrm{C}_{6} \mathrm{H}_{13}$

$8, \mathrm{R}=-\mathrm{F}, \mathrm{R}^{\prime}=-\mathrm{C}_{8} \mathrm{H}_{17}$,

\section{Synthesis, optimization and characterization of BCDTC-AgNPs}

A solution of silver nanoparticles (AgNPs) was synthesized by chemical reduction of dilute aqueous solution of silver nitrate, using sodium borohydride.

$\mathrm{AgNO}_{3}+\mathrm{NaBH}_{4} \rightarrow \mathrm{Ag}+1 / 2 \mathrm{H}_{2}+1 / 2 \mathrm{~B}_{2} \mathrm{H}_{6}+\mathrm{NaNO}_{3}$.

Compounds 1-8 were capped on naked AgNPs to obtain benzo[d]thiazol-2-ylcarbamodithioates-capped silver nanoparticles (BCDTC-AgNP ${ }^{\mathbf{1 - 8}}$ ). The colour of naked AgNP solution changed gradually from light yellow to brown after addition of capping agent, which was primary identification of formation of BCDTC-AgNPs (Guzman et al. 2009). The concentration optimization was further made by repeating the experiment with four different concentrations viz. $0.015,0.030,0.045$ and $0.060 \mathrm{mmol}$. The UV-Vis spectroscopy and transmission electron microscopy further revealed that $0.015 \mathrm{~mol}$ of compound 3-10 in $10 \mathrm{ml}$ of $25 \times 10^{-6} \mathrm{M}$ was optimum concentration for exact capping of AgNPs. This was supported by the observation that the excessive amount of carbamodithioates settled down after some days when the concentration was more than $0.015 \mathrm{~mol}$, whereas the BCDTC-capped silver nanoparticles at $0.015 \mathrm{mmol}$ concentration of capping agent were stable for long time.

In UV-Vis spectra a very pronounced plasmon absorption band of naked silver nanoparticles appeared at $405 \mathrm{~nm}$ $\left(\lambda_{\max }\right)$ characteristic of a silver colloid as represented by curve (a) in Fig. 1. The curves (b-e) in the same figure corresponded to the $0.015,0.030,0.045$ and respectively. The broadness of the absorption band takes place with increase in concentration of BCDTCs, whereas there was a sharp peak with absorbance maxima at $401 \mathrm{~nm}$ at concentration $0.015 \mathrm{~mol}$ of BCDTC. It was relatively blue shifted with respect to naked AgNPs that were at $405 \mathrm{~nm}$ and indicated that after the capping, particle size reduced (Tong et al. 2006). And the broadened peaks (c-e) in the same spectrograph appeared due to the loss of surface plasmon resonance which is attributed to the formation of metal nanoparticles (Naz et al. 2014). $0.060 \mathrm{mmol}$ of BCDTC in $10 \mathrm{ml}$ of $2.5 \times 10^{-6} \mathrm{M} \mathrm{AgNPs}$,
Fig. 1 UV-visible spectral analysis

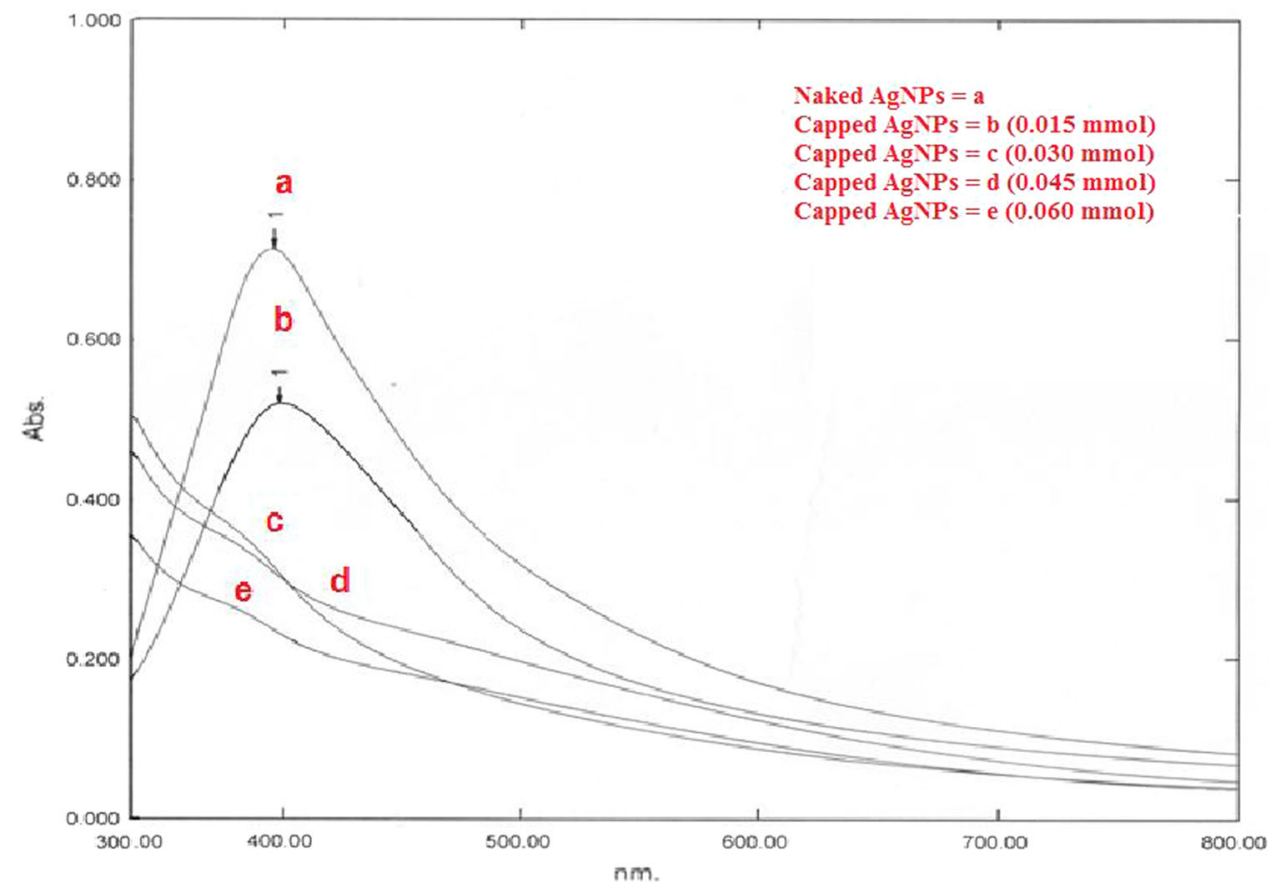



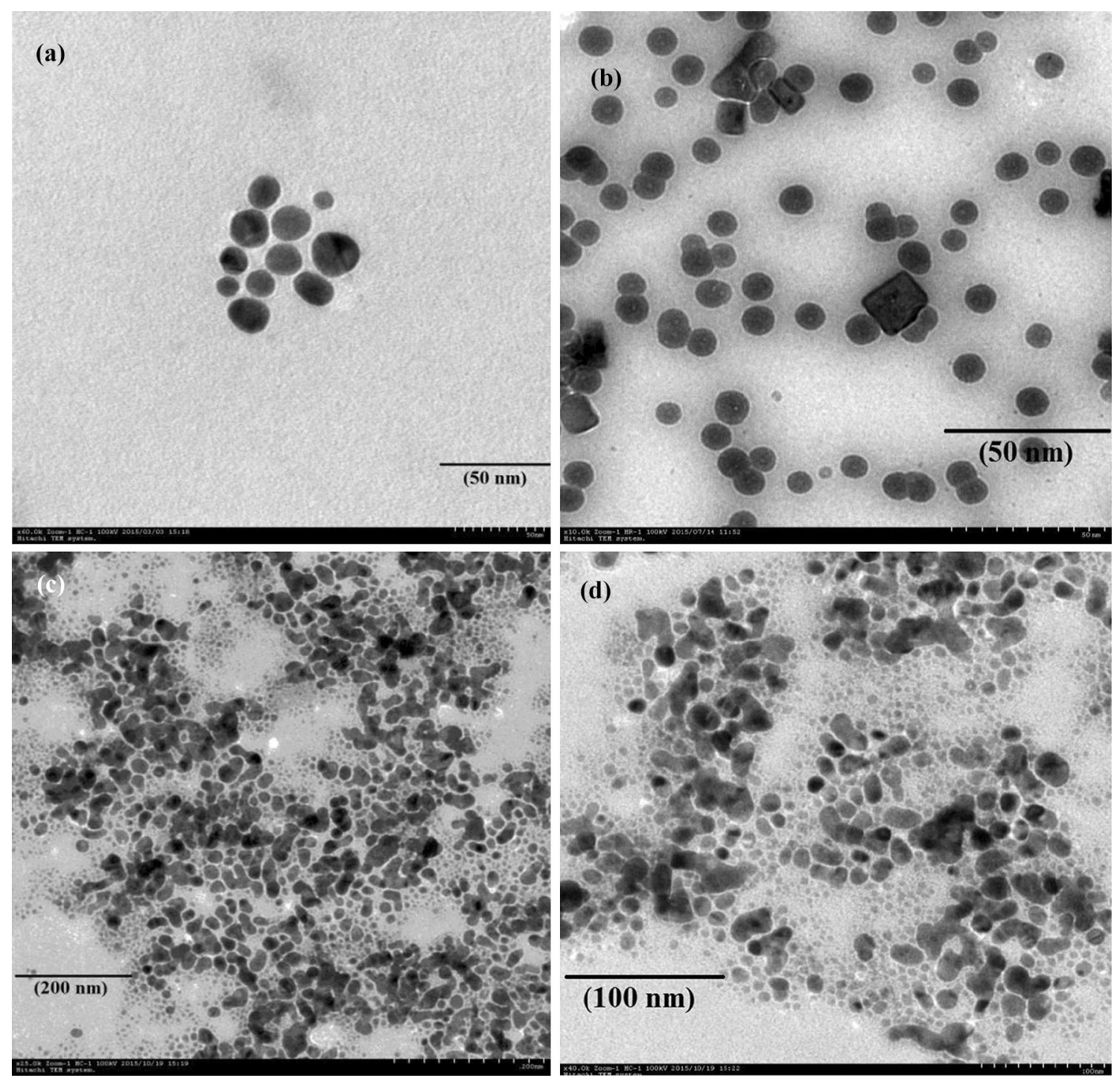

Fig. 2 a TEM micrograph of naked AgNPs; b BCDTC-AgNP ${ }^{3}$ at $0.015 \mathrm{~mol}$; $\mathbf{c}$ BCDTC-AgNP ${ }^{\mathbf{3}}$ at $0.045 \mathrm{~mol}$; $\mathbf{d}_{\mathrm{BCDTC}-\mathrm{AgNP}}^{\mathbf{3}}$ at $0.060 \mathrm{~mol}$

The morphology and particle size of BCDTC-AgNPs were studied by transmission electron microscopy (TEM). TEM micrograph depicted that prepared naked nanoparticles were in spherical shape and uniformly distributed without any agglomeration with diameter in range of 25-30 nm (Figs. 2a, 3a). The capped particles had reduced size in a range $20-25 \mathrm{~nm}$ at $0.015 \mathrm{~mol}$ of capping agent, with no extra BCDTC sited around the nanoparticles (Fig. 2b), whereas when the concentration of BCDTCs was $0.030,0.045$ and $0.060 \mathrm{~mol}$, an excessive amount of material was witnessed around the nanoparticles in the TEM micrograph (Fig. 2c-d). The standard deviation in the size of dispersed particles is witnessed in form of histogram (Fig. 3). The silver nanoparticles were synthesized by chemical reduction method in all the samples. During addition of capping agent they were sonicated resulting in their further dispersal to some extent and capping molecules do not allow their aggregation leading to their reduced size (Saha et al. 2016).

The synergistic effect of conjugation of two precursors was seen both in stability and size of the particles, whereas there is negligible effect of increased size of alkyl chain on the stabilization and size of the conjugates. The nanoformulations were found to be stable even after 8 months of standing making it a good choice in terms of high shelf-life.

\section{In silico toxicity analysis}

The toxicity analysis, made by using the toxtree v2.6.6 software, revealed that all the compounds belong to class III level of toxicity, which was at par with the toxicity of standard fungicide, Tilt. The results were obtained on the basis of Cramer's rule of toxicity analysis (Patlewicz et al. 2008). 


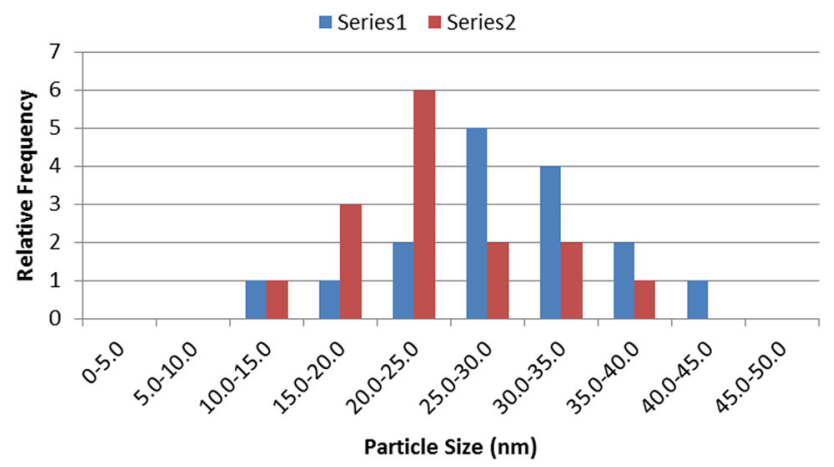

Fig. 3 Size distribution of naked AgNPs (series 1) and BCDTC$\mathrm{AgNP}^{3}$ at $0.015 \mathrm{~mol}$ (series 2)

\section{Antifungal evaluation}

Mycobiocidal efficacy of the series of BCDTC-AgNP ${ }^{1-8}$ was evaluated against four phytopathogenic fungi viz. Pyricularia grisea, D. oryzae, $F$. moniliforme and $U$. virens by spore germination inhibition technique and results were compared with naked AgNps (Table 1) and BCDTC (1-8) (Table 2). The results expressed are in terms of $\mathrm{EC}_{50}$ values $(\mu \mathrm{mol} / \mathrm{ml})$.

The naked silver nanoparticles were practically inactive at $25 \times 10^{-3} \mu \mathrm{mol} / \mathrm{ml}$ concentrations and, therefore, their $\mathrm{EC}_{50}$ values were expected to be much higher than this value against all the test fungi. The surface functionalization of AgNPs with myco-active BCDTC (1-8) (Ghatelwal et al. 2017) revealed very promising results. Against, $P$. grisea BCDTC-AgNP ${ }^{3}$ and BCDTC-AgNP ${ }^{5}$ were found to be the effective with $\mathrm{EC}_{50}$ values, $0.20 \times 10^{-3}$ and $0.13 \times 10^{--}$ ${ }^{3} \mu \mathrm{mol} / \mathrm{ml}$, respectively. BCDTC-AgNP ${ }^{1}$ was the most active nanoconjugate against $D$. oryzae, $F$. moniliforme and $U$. virens with $\mathrm{EC}_{50}$ values $0.10 \times 10^{-3} \mu \mathrm{mol} / \mathrm{ml}$, in all the cases. There was multifold enhancement in the fungitoxicity potential of AgNps when capped with BCDTC revealing favourable effect of conjugation. The results are in consonance with the earlier reports where the AgNP conjugates with most active compounds gave augmented biopotential than the bare ones (Saha et al. 2016; Vyas et al. 2015; Kumar and Poornachandra 2015), even against resistant strains of micro-organisms (Gajbhiye et al. 2009; Tiwari et al. 2014).

Comparison of these nanoconjugates in terms of drug equivalence of BCDTCs gave enthusiastic results (Table 2). Against $P$. grisea, compound $\mathbf{5}$ was the most active compound with $\mathrm{EC}_{50}$ value $0.38 \mu \mathrm{mol} / \mathrm{ml}$ but in coated form this value reduced to $0.075 \mu \mathrm{mol} / \mathrm{ml}$, which revealed five times increase in the potential in nanodispersed formulation (excluding the contribution of AgNps in terms of activity or bulk). Against $D$. oryzae, $F$. moniliforme and $U$. virens, compound $\mathbf{1}$ inflicted the maximum inhibition of fungal spores with values $0.13,0.32$ and $0.58 \mu \mathrm{mol} / \mathrm{ml}$ which got reduced on nanodispersion on silver nanoparticles, to 0.062 ,
0.062 and $0.075 \mu \mathrm{mol} / \mathrm{ml}$, giving threefold increase in the mycocidal potential of all the test nanoconjugates. The results of most of the nanoformulated BCDTCs were also far better than the standard fungicides, Tilt and Bavistin used against these fungi.

This was attributed to the improved dispersibilty of waterinsoluble BCDTC leading to more number of molecules available (active) per unit volume (Santra 2014), leading to their better bioavailability (Tiwari et al. 2014). The AgNps also affect the bioefficacy by acting as carrier, taking the active molecules into the interior of the diseased tissues with favourable effects (Sevilla et al. 2009). Our results were on the same line as the previous reported literature which indicated the effect of nanoconjugation on the bioefficacy non nanoformulations of bioactive compounds (Saha et al. 2016; Vyas et al. 2015; Kumar and Poornachandra 2015).

The individual investigation of antifungal screening clearly revealed that most of lower alkyl chain substituted benzo[d]thiazol-2ylcarbamodithioates showed significant inhibition of germination against all the test fungi. Further, chloro-substituted benzothiazol-2-ylcarbamodithioates derivatives were found to be more effective than their floro analogues. On the basis of alkylation, the butyl- and hexylsubstituted derivatives gave better results (Ghatelwal et al. 2017).

\section{Conclusion}

Silver sprays were not recommended till date due to various application issues but BCDTC-AgNP nanoconjugates can be efficiently used for localised seed treatments for eradication of fungal menace. They may act as excellent replacement of organo-mercurials (banned) with much lower toxicity hazards.

The study further advocates the exploitation of the results by replacement of expensive Ag metal with costeffective metals which are essential micro or macro nutrients of the plant kingdom. This could be able to fulfil the twin objective of nutrition and antifungal activity by single moiety, keeping the risk of metal accumulation and toxicity at bay. Our endeavours in the direction are under way.

Acknowledgements We thank DST-Nanomission for the financial support.

Open Access This article is distributed under the terms of the Creative Commons Attribution 4.0 International License (http:// creativecommons.org/licenses/by/4.0/), which permits unrestricted use, distribution, and reproduction in any medium, provided you give appropriate credit to the original author(s) and the source, provide a link to the Creative Commons license, and indicate if changes were made. 


\section{References}

Aashritha S (2013) Synthesis of silver nanoparticles by chemical reduction method and their antifungal activity. Int res $\mathbf{J}$ Pharm 4(10): 111

Bordes P, Pollet E, Averous L (2009) Nano-biocomposites: biodegradable polyester/nanoclay systems. Prog Polym Sci $34: 125$

Duncan R (2003) The dawning era of polymer therapeutics. Nat Rev Drug Disc 2:347

Fabrega J, Luoma SN, Tyler CR, Galloway TS, Lead JR (2011) Silver nanoparticles: behaviour and effects in the aquatic environment. Environ Int 37:517

Faraji AH, Wipf P (2009) Nanoparticles in cellular drug delivery. Bioorg Med Chem 17:2950

Ferrari M (2005) Cancer nanotechnology: opportunities and challenges. Nat Rev Cancer 5:161

Finney DJ (1971) Probit analysis, 3rd edn. Cambridge University Press, Cambridge

Gajbhiye M, Kesharwani J, Ingle A, Gade A, Rai M (2009) Fungus mediated synthesis of silver nanoparticles and its activity against pathogenic fungi in combination of fluconazole. Nanomedicine $5: 382$

Ghatelwal SR, Sidhu A, Gumber K, Sharma VK (2017) Solid phase synthesis of benzo[d]thiazol-2-ylcarbamodithioates and their evaluation as potential antifungals. IRJC 18:30-37

Gumber K, Sidhu A, Kumar V (2015) Green synthesis of thiazol2ylthiazolidin-4-ones as potential antifungals. Russ J Appl Chem 88:2065

Guzman MG, Dille J, Godet S (2009) Synthesis of silver nanoparticles by chemical reduction method and their antibacterial activity. Int J Chem Biomol Engg 2:104-111

Kanhed P, Birla S, Gaikwad S, Gade A, Seabra AB, Rubilar O, Duran N, Rai M (2014) In Vitro antifungal efficacy of copper nanoparticles against selected crop pathogenic fungi. Mater Lett 115:13

Kora AJ, Rastogi L (2013) Enhancement of antibacterial activity of capped silver nanoparticles in combination with antibiotics, on model gram-negative and gram-positive bacteria. Bioinorg Chem Appl 2013:1

Kukreja S, Sidhu A, Sharma VK (2016) Synthesis of novel 7-fluoro3-substituted-1,2,4-triazolo[3,4-b]benzothiazoles (FTBs) as potent antifungal agents: molecular docking and in silico evaluation. Res Chem Int 42:1

Kumar CG, Poornachandra Y (2015) Biodirected synthesis of miconazole-conjugated bacterial silver nanoparticles and their application as antifungal agents and drug delivery vehicles. Coll Surf B Biointerface 125:110

Liversidge M, Liversidge EGG, Cooper ER (2003) Nanosizing: a formulation approach for poorly-water-soluble compounds. Eur J Pharm Sci 18:113
Lok CN, Ho CM, Chen R (2006) Proteomic analysis of the mode of antibacterial action of silver nanoparticles. J Proteom Res 5:916

Naz SS, Shah MR, Islam NU, Khan A, Nazir S (2014) Qaisar S and Alam S S (2014) Synthesis and bioactivities of silver nanoparticles capped with 5-Amino- $\beta$-resorcylic acid hydrochloride dehydrate. J Nanobiotech 12:34

Neu HC (1992) The crisis in antibiotic resistance. Science 257:1064

Patlewicz G, Jeliazkova N, Safford RJ, Worth AP, Aleksiev B (2008) An evaluation of the implementation of the Cramer classification scheme in the Toxtree software. Environ Res 19:495

Saha S, Gupta B, Gupta K, Chaudhuri MG (2016) Production of putrescine-capped stable silver nanoparticle: its characterization and antibacterial activity against multidrug-resistant bacterial strains. Appl Nanosci 6(8):1137

Santra S (2014) silica based antifungal and antibacterial nanoformulations. US Patent 8632811B1

Sevilla P, Garcia-Blanco F, Garcia-Ramos JV, Sanchez-Cortes S (2009) Aggregation of antitumoral drug emodin on Ag nanoparticles: SEF, SERS and fluorescence lifetime experiments. Phys Chem Chem Phys 11:8342

Sidhu A, Kukreja S (2015) Synthesis of novel fluorinated benzothiazol-2-yl-1,2,4-triazoles: molecular docking, antifungal evaluation and in silico evaluation for SAR. Arab J Chem (accepted)

Sidhu A, Khushbu G, Kumar V (2015) Synthesis and structure activity relationship of substituted thiazoles. Agric Res J 52:42

Sidhu A, Sharma P, Gumber K, Sharma VK (2016) Synthesis and Antifungal evaluation of benzothiazol-2ylcarbamodithioates against covered smut and loose smut infections in barley and wheat. Plant Dis Res 31:114

Stewart PS, Costerton JW (2001) Antibiotic resistance of bacteria in biofilms. Lancet 358:135

Tiwari V, Khokar MK, Tiwari M, Barala S, Kumar M (2014) Antibacterial activity of polyvinylpyrrolidone capped silver nanoparticles on the carbapenem resistant strain of Acinetobacter baumannii. J Nanomed Nanotechnol 5:1

Tong CM, Chen W, Sun J, Ghosh D, Chen S (2006) Dithiocarbamtecapped silver nanoparticles. J Phys Chem B 110:19238

Vyas JD, Vyas HK, Makwana AB (2015) Preparation and characterisation of dithiocarbamates based calix [4] pyrrole assemblies on Ag nanoparticles: potential antimicrobial agent. Int J Sci Tech Manage 4(1):130

\section{Publisher's Note}

Springer Nature remains neutral with regard to jurisdictional claims in published maps and institutional affiliations. 